\title{
PENGEMBANGAN TITIK MIQUEL DALAM PADA SEBARANG SEGILIMA
}

\author{
Zukrianto', Okta Dinata ${ }^{2}$, Mohammad Soleh ${ }^{3}$, Ade Novia Rahma ${ }^{4}$, Rahmawati \\ 1,2,3,4,5 Program Studi Matematika, UIN Sultan Syarif Kasim Riau \\ zukrianto@uin-suska.ac.id
}

\begin{abstract}
The Miquel theorem is a theorem that applies to a triangle, namely the inner Miquel theorem and the outer Miquel theorem triangles-then developed on the quadrilateral. As of this writing, it is developed in any of the pentagons. Miquel's theorem development in any pentagon is divided into two cases, namely in the convex and non-convex pentagons. This process begins with the construction of the inner Miquel point in any triangle using the GeoGebra application. While proving the internal Miquel theorem for any pentagon uses a simple concept, namely the concept of circles and cyclic rectangles so that five circles intersect at a point called the inner Miquel point at any pentagon.
\end{abstract}

Keywords: Convex pentagon, Non-convex pentagon, Miquel

\begin{abstract}
ABSTRAK Teorema Miquel pada dasarnya merupakan suatu teorema yang berlaku pada sebuah segitiga yakni teorema Miquel dalam dan teorema Miquel luar segitiga. Kemudian dikembangkan pada segiempat. Pada tulisan ini, dikembangkan pada sebarang segilima. Pengembangan teorema Miquel dalam pada sebarang segilima dibagi menjadi dua kasus, yaitu pada segilima konveks dan segilima tidak konveks. Proses ini dimulai dengan pengkontruksian titik Miquel dalam pada sebarang segilima dengan menggunakan aplikasi geogebra, sedangkan untuk pembuktian teorema Miquel dalam pada sebarang segilima menggunakan konsep sederhana yaitu konsep lingkaran dan segiempat siklik sehingga ditemukan lima buah lingkaran berpotongan di satu titik yang disebut titik Miquel dalam pada sebarang segilima.
\end{abstract}

Kata-kata Kunci : Segilima koveks, Segilima non konveks, Teorema Miquel.

\section{PENDAHULUAN}

Geometri menurut Kamus Besar Bahasa Indonesia (Departemen Pendidikan Nasional, 2008), adalah cabang matematika yang menerangkan sifat-sifat garis, sudut, bidang dan ruang. Salah satu objek kajian Geometri adalah segitiga. Segitiga merupakan suatu bangun datar yang mempunyai tiga buah sisi dan tiga buah sudut (Mashadi, 2012). Kemudian Iswadji dan Mukhlisin (2010) menyatakan bahwa jika terdapat tiga buah titik yang tidak segaris, dua-dua dihubungkan oleh sebuah ruas garis, maka terdapat tiga buah ruas garis. Gabungan tiga buah ruas garis ini disebut segitiga. Ketiga buah ruas garis itu disebut sisi. Ketiga buah titik itu disebut titik sudut. Jumlah panjang ketiga sisi itu disebut keliling segitiga. Pada sebuah segitiga juga terdapat garis-garis istimewa dalam segitiga yaitu: garis tinggi, garis berat, garis bagi dan garis sumbu. 
Dalam bidang geometri, terdapat suatu teorema yang membahas tentang segitiga yaitu Teorema Miquel. Teorema ini pada awalnya diterapkan pada bangun datar segitiga yang dibahas oleh Walles pada tahun 1799 dan kemudian dibuktikan oleh Miquel pada tahun 1838 (Villier, 2014). Posamentier dan Lehmann (2012) menyatakan Teorema Miquel dikontruksi pada sebarang segitiga kemudian dipilih sebarang titik pada setiap sisinya, maka lingkaran yang melalui setiap vertex dan titik-titik yang berada pada sisi yang berdekatan berpotongan di satu titik yang disebut titik Miquel.

Hasil penelitian Lydia Afritalia, dkk (2017) membahas tentang pengembangan titik Miquel Luar pada sebarang segiempat. Penelitian tersebut membahas bagaimana mengkontruksi titik Miquel Luar pada segiempat konveks, tidak konveks dan cara pembuktiannya seperti yang terlihat pada Gambar 1 . Lingkaran $l_{1}, l_{2}, l_{3}$ dan $l_{4}$ berpotongan di titik $M$.

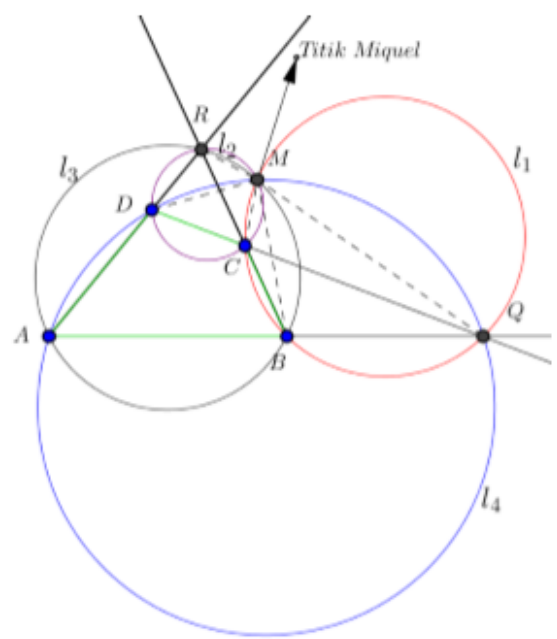

\section{Gambar 1. Titik Miquel Luar Segiempat Konveks}

Selanjutnya Pengembangan titik Miquel Dalam pada sebarang segiempat oleh Delisa Pratiwi, akk (2018). Penelitian tersebut membahas bagaimana mengkontruksi titik Miquel dalam pada segiempat konveks, tidak konveks dan cara pembuktiannya. Seperti yang terlihat pada Gambar 2. lingkaran $l_{1}, l_{2}, l_{3}$ dan $l_{4}$ berpotongan di titik $M$.

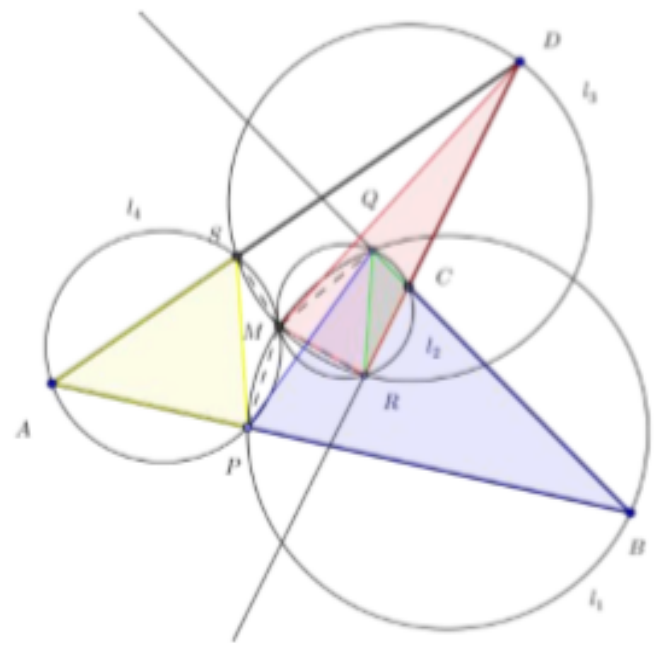

Gambar 2. Titik Miquel Dalam Segiempat Tidak Konveks 
Berdasarkan hasil-hasil penelitian yang telah diuraikan, maka pada penelitian ini membahas lebih lanjut mengenai pengembangan titik Miquel pada sebarang segilima. Segilima merupakan salah satu objek kajian Geometri. Segilima adalah gabungan lima ruas garis yang sepasang-sepasang bertemu pada ujung-ujung ruas garis tersebut dan setiap ruas garis pasti bertemu dengan dua ruas garis yang berbeda. Ruas-ruas garis tersebut disebut sisi-sisi segilima dan sudut-sudut yang dibentuk oleh pasangan-pasangan sisi-sisi tersebut disebut sudut-sudut segilima (Situmorang dan Lestari, 2014).

\section{METODE PENELITIAN}

Metode penelitian yang digunakan yaitu studi literatur dan metode eksperimen dengan aplikasi Geogebra. Geogebra dikembangkan oleh Markus Hohenwarter. Menurut Hohenwarter (2008), Geogebra adalah program komputer untuk membelajarkan matematika khususnya geometri dan aljabar. Pembuktian titik Miquel dalam pada segilima konveks dan segilima tidak konveks dengan menggunakan pendekatan lingkaran dan segiempat siklik. Lingkaran adalah himpunan semua titik yang membentuk lengkungan tertutup, dimana titik-titik pada lengkungan tersebut berjarak sama terhadap suatu titik tertentu yang disebut titik pusat lingkaran (Mashadi, 2015). Pada sebuah lingkaran dapat dikontruksi garis yang menghubungkan dua titik pada kelengkungan lingkaran yang disebut dengan tali busur (Mukarromah, 2014). Kemudian menurut Samsumarlin (2017) segiempat siklik atau disebut juga dengan segiempat tali busur jika dan hanya jika setiap titik sudutnya terletak pada satu lingkaran. Selanjutnya diberikan langkah-langkah pengembangan teorema Miquel dalam segilima konveks dan segilima tidak konveks yang terbagi dalam dua bagian, yakni mengkontruksi Titik Miquel dalam pada segilima konveks dengan cara:

1. Diberikan sebuah segilima konveks, pilih sebarang titik sudut/vertex dan 2 buah titik yang terletak pada sisi yang berdekatan dengan vertex. Konstruksi lingkaran yang melalui vertex dan kedua titik yang dipilih.

2. Kemudian konstruksi lingkaran dari vertex, salah satu titik yang berdekatan maka kedua lingkaran akan berpotongan di dua titik. Sehingga diperoleh sebuah titik pada sisi segilima konveks lainnya.

3. Konstruksi lagi lingkaran dari vertex, salah satu titik berdekatan dan perpotongan dua lingkaran sebelumnya. Sehingga diperoleh sebuah titik lainnya pada segilima.

4. Konstruksi lagi lingkaran dari vertex, salah satu titik berdekatan dan perpotongan lingkaran sebelumnya. Sehingga diperoleh sebuah titik lainnya pada segilima.

5. Kontruksikan lagi lingkaran dari vertex dan titik yang berdekatan sehingga kelima lingkaran berpotongan di satu titik yang disebut dengan titik Miquel.

Kemudian dilanjutkan dengan mengkontruksi Titik Miquel dalam pada segilima tidak konveks dengan cara: 
1. Diberikan sebuah segilima tidak konveks, pilih sebarang titik sudut/vertex dan 2 buah titik yang terletak pada sisi yang berdekatan dengan vertex. Konstruksi lingkaran yang melalui vertex dan kedua titik yang dipilih.

2. Kemudian konstruksi lingkaran dari vertex, salah satu titik yang berdekatan maka kedua lingkaran akan berpotongan di dua titik. Sehingga diperoleh sebuah titik lainnya pada perpanjangan sisi segilima tidak konveks lainnya.

3. Konstruksi lagi lingkaran dari vertex, salah satu titik berdekatan dan perpotongan dua lingkaran sebelumnya. Sehingga diperoleh sebuah titik lainnya pada perpanjangan sisi segilima.

4. Konstruksi lagi lingkaran dari vertex, salah satu titik berdekatan dan perpotongan lingkaran sebelumnya. Sehingga diperoleh sebuah titik lainnya pada perpanjangan sisi segilima.

5. Kontruksikan lagi lingkaran dari vertex dan titik yang berdekatan sehingga kelima lingkaran berpotongan di satu titik yang disebut dengan titik Miquel.

\section{HASIL DAN PEMBAHASAN}

Pada bagian ini dibahas mengenai bagaimana cara mengkontruksi titik Miquel dalam pada segilima konveks dengan menggunakan aplikasi geogebra dan cara pembuktiannya serta cara mengkontruksi titik Miquel dalam pada segilima tidak konveks dengan menggunakan aplikasi geogebra dan cara pembuktiannya.

\section{Mengkontruksi Titik Miquel Dalam Pada Segilima Konveks}

Teorema 1. Diberikan sebarang segilima konveks $A B C D E$. Pilih berturut-turut sebarang titik $F, G, H$, dan $I$ masing-masing pada sisi $A B, B C, C D$, dan $D E$. Jika $M$ adalah titik potong lingkaran luar $\triangle B F G$, lingkaran luar $\triangle C G H$, lingkaran luar $\triangle D H I$ dan lingkaran luar $\Delta$ $E I J$, maka lingkaran luar $\triangle A F J$ juga melalui titik $M$.

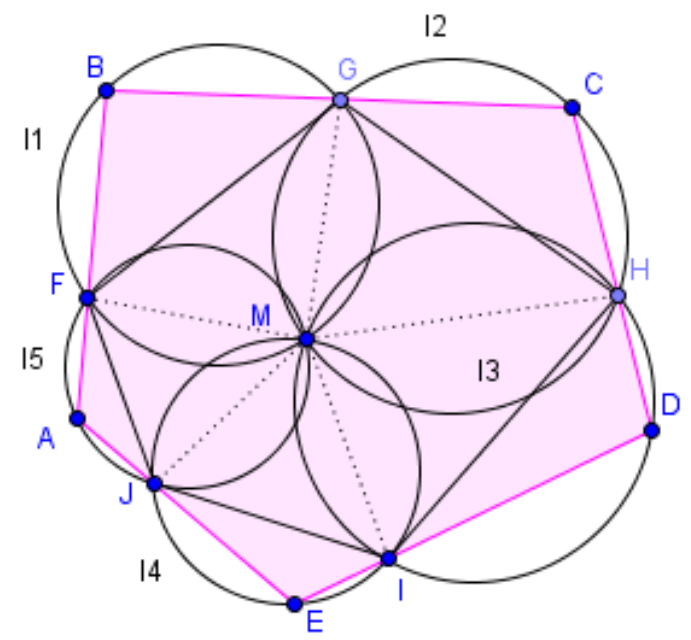

\section{Gambar 3. Titik Miquel Dalam Segilima Konveks}

Bukti. Perhatikan Gambar 3. Titik $M$ merupakan titik perpotongan lingkaran $l_{1}, l_{2}, l_{3}$ dan $l_{4}$. Kontruksi garis $F M, G M, H M$, dan IM maka BFMG,CGMH,DHMI dan EIMJ adalah siklik. Akan ditunjukkan bahwa segiempat $A J M F$ juga siklik.

$B F M G$ adalah segiempat siklik, maka: 


$$
\angle F M G=180^{\circ}-\angle F B G
$$

CGMHadalah segiempat siklik, maka:

$$
\angle G M H=180^{\circ}-\angle G C H
$$

DHMIadalah segiempat siklik, maka:

$$
\angle H M I=180^{\circ}-\angle H D I
$$

EIMJadalah segiempat siklik, maka:

$$
\angle I M J=180^{\circ}-\angle I E J
$$

Dengan menjumlahkan persamaan (1), persamaan (2), persamaan (3), dan persamaan (4) diperoleh:

$$
\begin{aligned}
& \angle F M G+\angle G M H+\angle H M I+\angle I M J=\left(180^{\circ}-\angle F B G\right)+\left(180^{\circ}-\angle G C H\right)+ \\
& \left(180^{\circ}-\angle H D I\right)+\left(180^{\circ}-\angle I E J\right) \\
& \angle J M F+\angle F M G+\angle G M H+\angle H M I+I M J=360^{\circ} \\
& \angle J M F=360^{\circ}-\angle F M G-\angle G M H-\angle H M I-\angle I M J \\
& \angle J M F=360^{\circ}-(\angle F M G+\angle G M H+\angle H M I+\angle I M J) \\
& =360^{\circ}-\left(720^{\circ}-(\angle F B G+\angle G C H+\angle H D I+\angle I E J)\right) \\
& =360^{\circ}-720^{\circ}+\angle F B G+\angle G C H+\angle H D I+\angle I E J \\
& \angle J M F=-360^{\circ}+\angle F B G+\angle G C H+\angle H D I+\angle I E J
\end{aligned}
$$$$
\angle F M G+\angle G M H+\angle H M I+\angle I M J=720^{\circ}-(\angle F B G+\angle G C H+\angle H D I+\angle I E J)
$$

Pada sebuah segilima $A B C D E$, berlaku:

$$
\begin{aligned}
& \angle A B C+\angle B C D+\angle C D E+\angle D E A+\angle E A B=540^{\circ} \\
& \angle A B C+\angle B C D+\angle C D E+\angle D E A=540^{\circ}-\angle E A B \\
& \angle F B G+\angle G C H+\angle H D I+\angle I E J=540^{\circ}-\angle J A F
\end{aligned}
$$

Maka dari persamaan (4.5) dan (4.6), diperoleh:

$$
\begin{aligned}
\angle J M F & =-360^{\circ}+540^{\circ}-\angle E A B \\
& =180^{\circ}-\angle E A B \\
\angle J M F+\angle E A B & =180^{\circ}
\end{aligned}
$$

Terbukti $A J M F$ juga merupakan segiempat siklik. Sehingga lingkaran $l_{1}, l_{2}, l_{3}, l_{4}$ dan $l_{5}$ berpotongan pada titik $M$ atau titik Miquel.

\section{Mengkontruksi Titik Miquel Dalam Pada Segilima Tidak Konveks}

Teorema 2. Diberikan sebarang segilima tidak konveks $A B C D E$. Pilih berturut-turut sebarang titik $P, Q, R$ dan $S$ masing-masing pada sisi $A E$, sisi $E D$, perpanjangan sisi $D C$ dan pepanjangan sisi $C B$. Jika $M$ adalah titik potong lingkaran luar $\triangle E P Q$, lingkaran luar $\triangle D Q R$, lingkaran luar $\triangle C S R$ dan lingkaran luar $\triangle B S T$, maka lingkaran luar $\triangle A P T$ juga melalui titik $M$. 


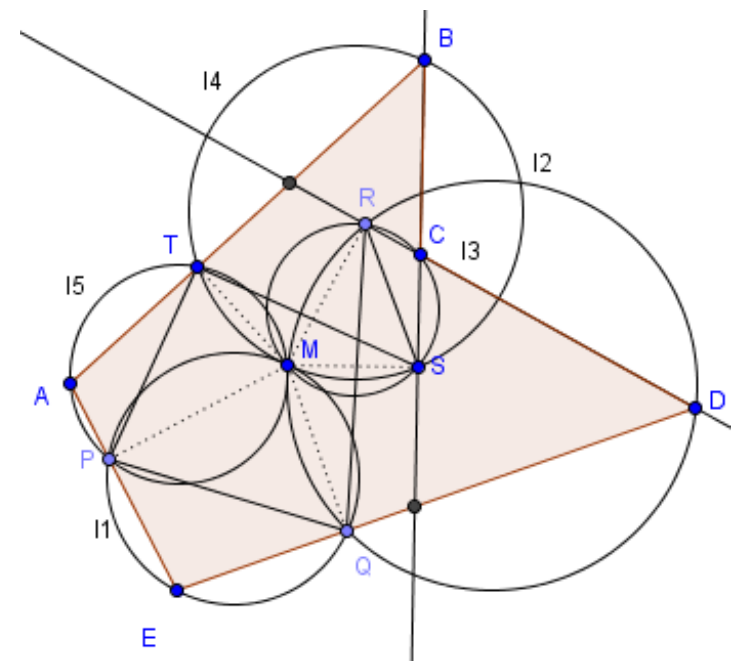

\section{Gambar 4. Titik Miquel Dalam Segilima Tidak Konveks}

Bukti: Perhatikan Gambar 4. Titik $M$ merupakan perpotongan lingkaran $l_{1}, l_{2}, l_{3}$ dan $l_{4}$. Kontruksi garis $Q M, R M, S M$, dan $T M$, maka EPMQ,DQMR,CSMR dan BSMT adalah segiempat siklik. Akan ditunjukkan bahwa segiempat ATMP juga siklik.

$E P M Q$ adalah segiempat siklik, maka:

$$
\angle P M Q=180^{\circ}-\angle P E Q
$$

$D Q M R$ adalah segiempat siklik, maka:

$$
\angle Q M R=180^{\circ}-\angle Q D R
$$

CSMR adalah segiempat siklik, maka:

$$
\angle S M R=180^{\circ}-\angle S C R
$$

$B S M T$ adalah segiempat siklik, maka:

$$
\angle S M T=180^{\circ}-S B T
$$

Dengan menjumlahkan persamaan (7), persamaan (8), persamaan (9), dan persamaan (10) diperoleh:

$$
\begin{aligned}
& \angle P M Q+\angle Q M R+\angle S M R+\angle S M T=\left(180^{\circ}-\angle P E Q\right)+\left(180^{\circ}-\angle Q D R\right)+ \\
&\left(180^{\circ}-\angle S C R\right)+\left(180^{\circ}-\angle S B T\right) \\
& \angle P M Q+\angle Q M R+\angle S M R+\angle S M T=720^{\circ}-(\angle P E Q+\angle Q D R+\angle S C R+\angle S B T)
\end{aligned}
$$

Perhatikan Gambar 4.12, diperoleh:

$$
\begin{aligned}
\angle P E Q+ & \angle Q D R+\angle S C R+\angle S B T+\angle P A T=540^{\circ} \\
& \angle P A T=540^{\circ}-(\angle P E Q+\angle Q D R+\angle S C R+\angle S B T)
\end{aligned}
$$

dan

$$
\begin{aligned}
\angle T M P+\angle P M Q & +\angle Q M R+\angle S M R+\angle S M T=360^{\circ} \\
\angle T M P & =360^{\circ}-\angle P M Q-\angle Q M R-\angle S M R-\angle S M T \\
& =360^{\circ}-\left(720^{\circ}-(\angle P E Q+\angle Q D R+\angle S C R+\angle S B T)\right) \\
& =360^{\circ}-720^{\circ}+\angle P E Q+\angle Q D R+\angle S C R+\angle S B T \\
& =(\angle P E Q+\angle Q D R+\angle S C R+\angle S B T)-360^{\circ} \\
\angle T M P & =(\angle P E Q+\angle Q D R+\angle S C R+\angle S B T)-360^{\circ}
\end{aligned}
$$


Dengan menjumlahkan persamaan (4.11) dan persamaan (4.12), diperoleh:

$$
\begin{aligned}
\angle P A T+\angle T M P= & 540^{\circ}-(\angle P E Q+Q D R+S C R+S B T)+ \\
= & \left.(5 P E Q+\angle Q D R+\angle S C R+\angle S B T)-360^{\circ}\right) \\
= & \left.180^{\circ} \quad+\quad \angle P E Q+\angle Q D R+\angle S C R+\angle S B T\right) \\
\angle P A T+\angle T M P=180^{\circ} &
\end{aligned}
$$

Terbukti $A P M T$ juga merupakan segiempat siklik. Sehingga lingkaran $l_{1}, l_{2}, l_{3}, l_{4}$ dan $l_{5}$ berpotongan pada titik $M$ atau titik Miquel.

\section{KESIMPULAN DAN SARAN}

Berdasarkan hasil dan pembahasan dapat disimpulkan bahwa titik miquel yang berlaku pada sebuah segitiga, ternyata dapat dikembangkan pada sebuah segilima yang diawali dengan pengkontruksian titik Miquel dalam dengan menggunakan aplikasi geogebra sehingga ditemukan kelima lingkaran berpotongan di satu titik yang disebut titik Miquel dan diakhiri dengan teorema Miquel dalam pada segilima konveks dan segilima tidak konveks. Pembuktian teorema ini menggunakan konsep lingkaran dan segiempat siklik.

\section{DAFTAR PUSTAKA}

Astuti, E. P., Ipa, M., Wahono, T., \& Ruliansyah, A. (2014). Analisis Perilaku Masyarakat Terhadap Kepatuhan Minum Obat Filariasis di Tiga Desa Kecamatan Majalaya Kabupaten Bandung Tahun 2013. Media Penelitian Dan Pengembangan Kesehatan, 24(4), 199-208.

Afritalia, L., Mashadi., \& Gemawati, S. (2017). Pengembangan Titik Miquel Luar Pada Sebarang Segiempat. Karismatika Vol. 3 No. 2.

Departemen Pendidikan Nasional. (2008). Kamus Besar Bahasa Indonesia. Jakarta.

Hohenwarter, M., et al. (2008). Teaching and learning Calculus WITH Free Dynamic Mathematics Software Geogebra. Tersedia. http://www.publications.uni.lu/ record/2718/files/ICME11TSG16.pdf. diakses 6 januari 2021.

Iswadji, D., \& Mukhlisin, M. (2010). Geometri. Universitas Ahmad Dahlan, Yogyakarta.

Mashadi. (2015). Geometri (edisi kedua).Unri Press, Pekanbaru.

Mashadi. (2012). Geometri. Pusbangdik Unri, Pekanbaru.

Mukaromah, S. (2014). Analisis Kemampuan Penalaran Siswa Kelas VIII MTs Qoidatul Marom Kauman Tulungagung Pada Materi Lingkaran Tahun Ajaran 2013/2014. http://repo.iain-tulungagung.ac.id/697/ diakses 6 Januari 2021

Samsumarlin. (2017). Segitiga dan Segiempat pada Geometri Datar Euclid Cevian Segitiga dan Segiempat Siklik. Edumaspul, Vol. 1, No. 1, pp. 15-22.

Posamentier, A. S., \& Lehmann, I. (2012). The Secreet of Triangle. Prometheus Books, New York.

Pratiwi, D., Mashadi., \& Gemawati, S. (2018). Pengembangan Titik Miquel Dalam Pada Sebarang Segiempat. Jurnal Eulid, Vol. 5, No.1, pp.1-133. 
Situmorang, E., \& Lestari, H.P. (2016). Jenis-jenis Segilima Bola dan Sifat-sifatnya. Jurnal Matematika-S1. Vol. 5, No. 5.

Villier M. D. (2014). A Variation of Miquel Theoreme and its generalization. The Mathematical Gazzete, 334-339. 